\title{
Biallelic inactivating variants in the GTPBP2 gene cause a neurodevelopmental disorder with severe intellectual disability
}

\author{
Aida M. Bertoli-Avella ${ }^{1} \cdot$ Jose M. Garcia-Aznar ${ }^{1} \cdot$ Oliver Brandau $^{1} \cdot$ Fahad Al-Hakami $^{2,3} \cdot$ Zafer Yüksel (iD $^{1}$ • \\ Anett Marais ${ }^{1}$ - Nana-Maria Grüning ${ }^{1}$. Lia Abbasi Moheb ${ }^{1} \cdot$ Omid Paknia $^{1} \cdot$ Nahla Alshaikh $^{3,4} \cdot$ Seham Alameer $^{3,5}$. \\ Makia J. Marafi $\mathbb{D}^{6} \cdot$ Fahd Al-Mulla $^{7} \cdot$ Nouriya Al-Sannaa ${ }^{8} \cdot$ Arndt Rolfs $^{1,9} \cdot$ Peter Bauer $^{1}$
}

Received: 12 July 2017 / Revised: 6 November 2017 / Accepted: 5 January 2018 / Published online: 15 February 2018

(c) European Society of Human Genetics 2018

\begin{abstract}
Congenital neurological disorders are genetically highly heterogeneous. Rare forms of hereditary neurological disorders are still difficult to be adequately diagnosed. Pertinent studies, especially when reporting only single families, need independent confirmation. We present three unrelated families in which whole-exome sequencing identified the homozygous non-sense variants c. $430[\mathrm{C}>\mathrm{T}] ;[\mathrm{C}>\mathrm{T}]$ p. $(\operatorname{Arg} 144 *)$, c. $1219[\mathrm{C}>\mathrm{T}] ;[\mathrm{C}>\mathrm{T}]$ p. $\left(\mathrm{Gln} 407^{*}\right)$ and c.1408[C $\left.>\mathrm{T}\right] ;[\mathrm{C}>\mathrm{T}]$ p. $(\operatorname{Arg} 470 *)$ in GTPBP2. Their clinical presentations include early onset and apparently non-progressive motor and cognitive impairment, and thereby overlap with findings in a recently described family harbouring a homozygous GTPBP2 splice site variant. Notable differences include structural brain abnormalities (e.g., agenesis of the corpus callosum, exclusive to our patients), and evidence for brain iron accumulation (exclusive to the previously described family). This report confirms pathogenicity of biallelic GTPBP2 inactivation and broadens the phenotypic spectrum. It also underlines that a potential involvement of brain iron accumulation needs clarification. Further patients will have to be identified and characterised in order to fully define the core features of GTPBP2-associated neurological disorder, but future approaches to molecular diagnosis of neurodevelopmental disorders should implement GTPBP2.
\end{abstract}

\section{Introduction}

For many common neurological disorders, a genetic contribution or even a monogenic aetiology has long been established [1]. For less frequent disease entities, similar progress is beginning to emerge thanks to the recent advances

These authors contributed equally: Aida M. Bertoli-Avella, Jose M. Garcia-Aznar, and Oliver Brandau.

Electronic supplementary material The online version of this article (https://doi.org/10.1038/s41431-018-0097-3) contains supplementary material, which is available to authorised users.

Aida M. Bertoli-Avella

aida.bertoli-avella@centogene.com

Centogene AG, Rostock, Germany

2 Molecular Medicine Section, King Abdulaziz Medical City, Ministry of National Guard Health Affairs, Jeddah, Saudi Arabia

3 King Saud Bin Abdulaziz University For Health Sciences, Ministry of National Guard Health Affairs,, Jeddah, Saudi Arabia

4 Pediatric Neurology Section, King Abdulaziz Medical City, Ministry of National Guard Health Affairs, Jeddah, Saudi Arabia in genomic technologies [2]. Identifying causative genes for ultra-rare neurological conditions, however, remains a great challenge. Many pertinent reports present only a single-small family or even only a single patient [3, 4], and a lack of subsequent confirmatory studies may cast some doubt on the validity of the proposed genotype-phenotype correlations.

As an example, a recent study suggested causality of biallelic GTPBP2 variants for a complex neurological phenotype [5]. The gene, which had not previously been involved in human inherited disease, was found to harbour a homozygous splice site variant in three affected siblings born to consanguineous parents from Iran. Clinical features observed in all patients included dystonia, ataxia, cognitive

5 Department of Pediatrics, King Abdulaziz Medical City, Ministry of National Guard Health Affairs, Jeddah, Saudi Arabia

6 Kuwait Medical Genetics Centre, Kuwait City, Kuwait

7 Genatak Center for Genomic Medicine, Kuwait City, Kuwait

8 John Hopkins Aramco Health Care, Pediatric Services, Dhahran, Saudi Arabia

9 Albrecht-Kossel-Institute for Neuroregeneration, Medical University Rostock, Rostock, Germany 


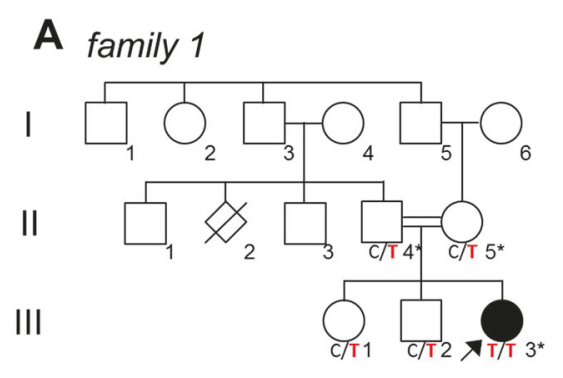

B

family 2

I

II

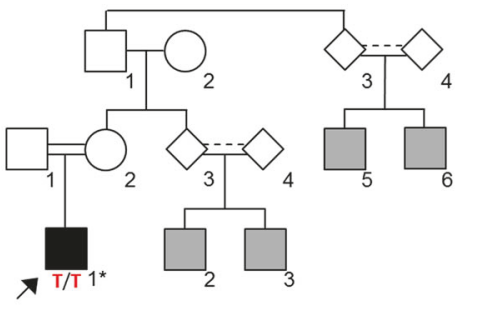

C

family 3

1

II

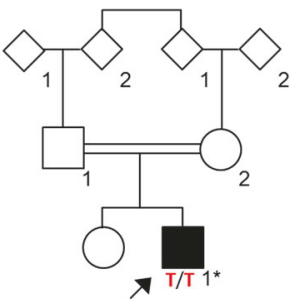

control
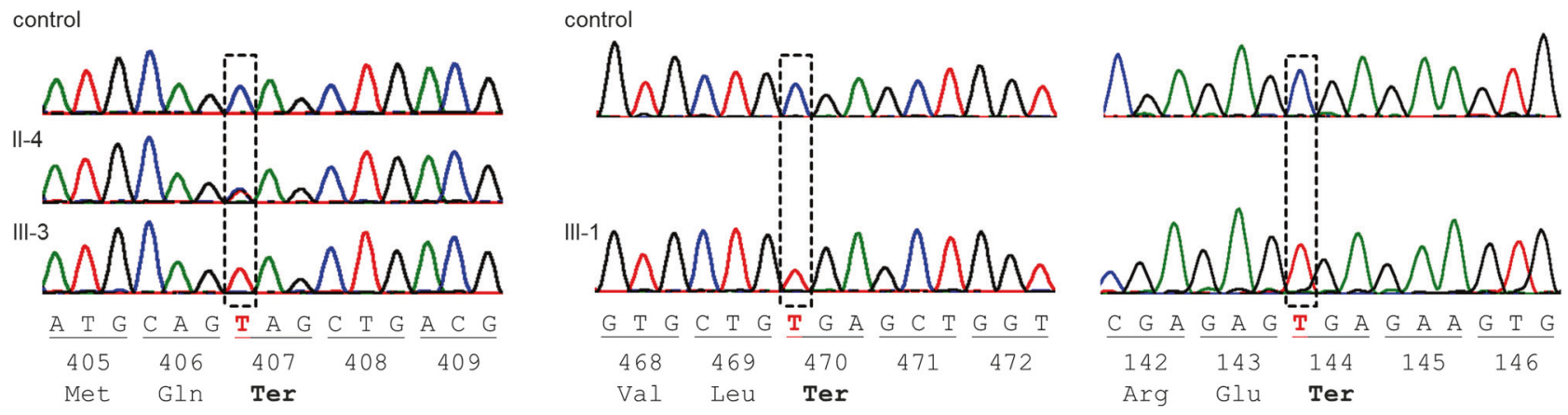

D
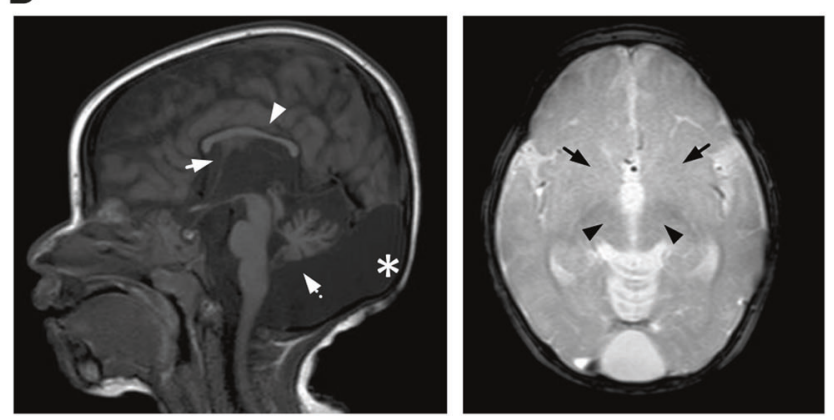

Fig. 1 Three families carrying homozygous GTPBP2 (NM_019096.4) non-sense variants. Stars denote individuals analysed by WES. Allelic status for the variants in question is provided below individual symbols in the pedigrees. Sequence traces confirming the primary WES data are shown to the right; the predicted consequences at protein are indicated below the traces. a Family 1 and variant c. $1219 \mathrm{C}>\mathrm{T}$. b Family 2 and variant c. $1408 \mathrm{C}>\mathrm{T}$. Several third and fourth-degree relatives of the index case are affected by a reportedly similar disease (grey symbols). Dotted relationship lines indicate that consanguinity is likely. c Family 3 and variant c.430C $>$ T. d Magnet resonance imaging

dysfunction, motor neuropathy, and retinal abnormalities, but also sparse, thin and brittle hair. Mild hypointensities in the Globus pallidus upon magnetic resonance imaging (MRI) were interpreted in favour of abnormal brain iron deposition. Despite partial overlap of some of the clinical symptoms to the phenotype of a Gtpbp2 knockout mouse (which, notably, carried a concomitant variant which affects function in a tRNA gene) [6], the authors recognised that confirming the causative nature of inactivating GTPBP2 variants requires identification of additional families [5].

We report three families in which distinct homozygous GTPBP2 non-sense variants are associated with a wide range of neurological and non-neurological manifestations.
E

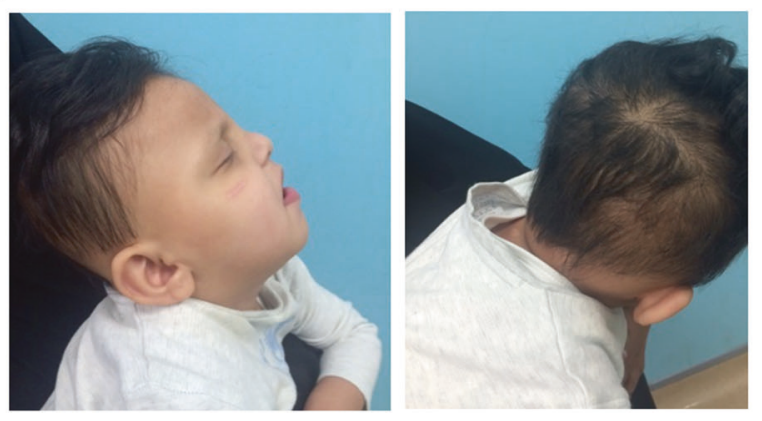

of the index patient III-3 from family 1 at age 6 years. On the left: sagittal T1-weighted spin-echo image discloses a thin corpus callosum (arrowhead) with absent rostrum (arrow), hypoplasia of cerebellar vermis (stippled arrow) and presence of mega cisterna magna (star). On the right: axial $\mathrm{T} 2 *$-weighted fast field-echo image (section through upper tectum) does not reveal evidence for specific hypointensities in the globus pallidus bilaterally (arrows) or in the substantia nigra (arrow heads). e Index patient from family 3 at age 2 years. Note dysmorphic features and sparse hair

Our findings not only confirm that biallelic inactivation of GTPBP2 is pathogenic, but also broaden the phenotypic spectrum of rare $G T P B P 2$-associated disorder.

\section{Patients and methods}

\section{Patients}

Parental consanguinity and/or positive family history suggested a genetic basis for the complex phenotypes observed in families 1, 2, and 3 (Fig. 1a, c); molecular genetic workup was therefore requested. In the single patient of family 1 , the 
Table 1 Genetic and clinical features of all presently and previously reported patients with GTPBP2-associated disorder

Patients reported by present study

\begin{tabular}{|c|c|c|c|c|c|c|}
\hline $\begin{array}{l}\text { Individual } \\
\text { patients }\end{array}$ & Index family 1 & Index family 2 & Index family 3 & DS100-03 & DS100-04 & DS100-05 \\
\hline $\begin{array}{l}\text { Homozygous } \\
\text { DNA variant in } \\
G T P B P 2 \\
\end{array}$ & c. $1219[\mathrm{C}>\mathrm{T}] ;[\mathrm{C}>\mathrm{T}]$ & c. $1408[\mathrm{C}>\mathrm{T}] ;[\mathrm{C}>\mathrm{T}]$ & c. $430[\mathrm{C}>\mathrm{T}] ;[\mathrm{C}>\mathrm{T}]$ & \multicolumn{3}{|c|}{ c. $1237-1[\mathrm{G}>\mathrm{T}] ;[\mathrm{G}>\mathrm{T}]$} \\
\hline $\begin{array}{l}\text { Predicted } \\
\text { alteration at } \\
\text { protein level }\end{array}$ & p. $\left(\mathrm{Gln} 407^{*}\right)$ & p. $(\operatorname{Arg} 470 *)$ & p. $\left(\operatorname{Arg} 144^{*}\right)$ & \multicolumn{3}{|c|}{ p.(Val413TrpfsTer3) } \\
\hline \multicolumn{7}{|l|}{ General } \\
\hline Consanguinity & Yes & Yes & Yes & Yes & & \\
\hline Family history & Negative & Positive & Negative & Positive & & \\
\hline $\begin{array}{l}\text { Age at last } \\
\text { examination }\end{array}$ & 6 yrs. & 10 yrs. & 2 yrs. & 34 yrs. & 30 yrs. & 29 yrs. \\
\hline Gender & Female & Male & Male & Female & Male & Male \\
\hline \multicolumn{7}{|c|}{ Biometry at birth } \\
\hline Weight & $2.7 \mathrm{~kg}$ (5th perc.) & $3 \mathrm{~kg}$ (10th perc) & NA & NA & & \\
\hline Height & NA & NA & NA & NA & & \\
\hline $\begin{array}{l}\text { Occipitofrontal } \\
\text { head } \\
\text { circumference }\end{array}$ & $\begin{array}{l}36.5 \mathrm{~cm} \text { at } 1 \text { month of age } \\
(25-50 \text { perc })\end{array}$ & NA & NA & NA & & \\
\hline \multicolumn{7}{|l|}{$\begin{array}{l}\text { Biometry at last } \\
\text { examination }\end{array}$} \\
\hline Weight & $16 \mathrm{~kg}(<3 \mathrm{rd}$ perc $)$ & $9.2 \mathrm{~kg} *(<5$ th perc $)$ & $12.65 \mathrm{~kg}$ (25th perc) & NA & & \\
\hline Height & $103 \mathrm{~cm}(<3 \mathrm{rd}$ perc $)$ & $76 \mathrm{~cm}^{*}$ (10th perc) & $88 \mathrm{~cm}$ (50th perc) & NA & & \\
\hline Occipitofrontal & $45 \mathrm{~cm}(<3 \mathrm{rd}$ perc $)$ & $42 \mathrm{~cm}^{*}(<3 \mathrm{rd}$ perc $)$ & $43.5 \mathrm{~cm}(<3 \mathrm{rd}$ perc $)$ & NA & & \\
\hline
\end{tabular}

et al. (ref. 5)

DS100-03 DS100-04 DS100-05

head

circumference

Development

Failure to thrive Yes

No

Motor

development

Intelectual

disability

(expressivity)

Regression

Neurologic

examination

Dystonia

No

Ataxia

No

Llimb spasticity Yes

Reflexes

Brisk

Tone

Seizures

Other

Increased in all limbs, joint stiffness, truncal hypotonia

Severe (no words, no social Severe smile)

No

Yes

No

No

Family published by Jaberi

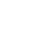

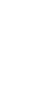


Table 1 (continued)

\begin{tabular}{|c|c|c|c|c|c|c|}
\hline \multirow[b]{2}{*}{$\begin{array}{l}\text { Individual } \\
\text { patients }\end{array}$} & \multicolumn{3}{|c|}{ Patients reported by present study } & \multicolumn{3}{|c|}{$\begin{array}{l}\text { Family published by Jaberi } \\
\text { et al. (ref. } 5 \text { ) }\end{array}$} \\
\hline & Index family 1 & Index family 2 & Index family 3 & DS100-03 & DS100-04 & DS100-05 \\
\hline Spine & Mild thoracolumbar scoliosis & $\begin{array}{l}\text { Dorsolumbar } \\
\text { kyphoscoliosis }\end{array}$ & Scoliosis & No & Scoliosis & Scoliosis \\
\hline Others & $\begin{array}{l}\text { Stiffness of interphalangeal } \\
\text { joints and knees, } \\
\text { equinovarus deformities }\end{array}$ & $\begin{array}{l}\text { Flexion deformity of } \\
\text { fingers (clenched hands), } \\
\text { bilateral talipes }\end{array}$ & Mild joint hypermobility & $\begin{array}{l}\text { None } \\
\text { reported }\end{array}$ & $\begin{array}{l}\text { None } \\
\text { reported }\end{array}$ & $\begin{array}{l}\text { Pectus } \\
\text { carinatum }\end{array}$ \\
\hline $\begin{array}{l}\text { Hearing } \\
\text { impairment }\end{array}$ & $\begin{array}{l}\text { No (normal auditory } \\
\text { brainstem response } \\
\text { audiometry) }\end{array}$ & No & No & $\begin{array}{l}\text { None } \\
\text { reported }\end{array}$ & & \\
\hline $\begin{array}{l}\text { Visual } \\
\text { impairment }\end{array}$ & $\begin{array}{l}\text { Yes (bilateral optic atrophy } \\
\text { left }>\text { right, strabismus, } \\
\text { nystagmus) }\end{array}$ & Yes (blindness) & Yes & $\begin{array}{l}\text { Yes } \\
\text { (retinal } \\
\text { anomalies) }\end{array}$ & $\begin{array}{l}\text { Yes } \\
\text { (retinal } \\
\text { anomalies) }\end{array}$ & $\begin{array}{l}\text { Yes (early } \\
\text { onset } \\
\text { cataracts) }\end{array}$ \\
\hline $\begin{array}{l}\text { Dysmorphic/ } \\
\text { other features }\end{array}$ & $\begin{array}{l}\text { Facial (depressed broad nasal } \\
\text { bridge, bi-temporal } \\
\text { narrowing, prominent ears), } \\
\text { midline hair defect }\end{array}$ & $\begin{array}{l}\text { Ectodermal dysplasia } \\
\text { (sparse scalp hair, scanty } \\
\text { eyebrows and eyelashes, } \\
\text { abnormal dentition) }\end{array}$ & $\begin{array}{l}\text { Facial (large low-set ears, small } \\
\text { nose, triangular mouth), sparse } \\
\text { scalp hair, sparse eyebrows, } \\
\text { hypodentition }\end{array}$ & Sparse, thin & $\mathrm{n}$ and brittle & hair \\
\hline \multicolumn{7}{|l|}{ Brain MRI } \\
\hline $\begin{array}{l}\text { Corpus } \\
\text { callosum } \\
\text { abnormalities }\end{array}$ & $\begin{array}{l}\text { Partial hypogenesis (rostrum } \\
\text { absent) }\end{array}$ & Agenesis & $\begin{array}{l}\text { Partial hypogenesis (rostrum } \\
\text { absent) }\end{array}$ & \multicolumn{3}{|c|}{ None described } \\
\hline Brain atrophy & Yes & Yes & Yes & \multicolumn{3}{|c|}{ None described } \\
\hline $\begin{array}{l}\text { Cerebellar } \\
\text { hypoplasia }\end{array}$ & $\begin{array}{l}\text { Yes (inferior vermian } \\
\text { hypoplasia) }\end{array}$ & None reported & Yes (cerebellar hypoplasia) & \multicolumn{3}{|c|}{ Yes (cerebellar vermian atrophy) } \\
\hline Dandy-Walker & Yes & None reported & No & \multicolumn{3}{|l|}{ No } \\
\hline
\end{tabular}
malformation

Mild hydrocephalus, hypoplastic pituitary gland
Abnormally large subarachnoid Hypointensities in globus pallidus spaces, subdural hemorrhage on and substantia nigra right side of frontoparietal area

NA not available

* Biometry taken at age of 16 months

primary clinical findings were failure to thrive, psychomotor retardation, visual impairment, and midline hair defect, whereas the index patient of family 2 had initially been clinically diagnosed with intellectual disability and ectodermal dysplasia. The patient from family 3 presented with developmental delay, seizures, microcephaly, dysmorphic features, abnormal tooth colour, and sparse hair. Magnet resonance imaging in the index patient of family 1 , as well as more detailed clinical re-evaluation of both index patients were initiated after identification of GTPBP2 variants. All genetic analyses were performed in concordance to the provisions of the German Gene Diagnostic Act (Gendiagnostikgesetz), and written informed consent was obtained from the patients' parents and referring clinicians for publication.

\section{DNA preparation and sequencing}

Genomic DNA from several members of family 1 (Fig. 1a) was prepared from leucocytes using a standard salting-out procedure. For the index patients of families 2 and 3 (Fig. 1b, c), genomic DNA was isolated from dried blood spots in filter cards (CentoCard) using the QIAamp DNA Blood Mini QIAcube Kit (Qiagen, Valencia, CA) according to the manufacturer's instructions. Whole-exome sequencing (WES) for all three index patients, as well as for the parents in family 1 was performed as described previously [7]. In short, the Nextera Rapid Capture Exome Kit (Illumina, San Diego, CA) or the SureSelect Human All Exon kit (Agilent, Santa Clara, CA) were used for enrichment, and a HiSeq4000 (Illumina) instrument for the actual sequencing; variants were annotated using Annovar (http://a nnovar.openbioinformatics.org) [8] and in-house ad hoc bioinformatics tools [7].

Considering parental consanguinity in all cases, we first filtered WES data for homozygous variants with minor allele frequencies $<1 \%$ in each of three public variation databases (1000 Genomes Project; Exome Variant Server; Exome Aggregation Consortium database), as well as in 
CentoMD and an internal database. CentoMD is Centogene's proprietary database, and includes data from nearly 140,000 individuals of diverse geographic origins [9]. Our internal database contains $~ 9000$ and 750 index cases (plus relatives) which have been analysed by WES and whole genome sequencing, respectively. This resulted in candidate gene lists that contained between 21 and 40 genes per family (Supplementary Table 1). Truncating variants (nonsense, frameshift, core 2 bp splice motifs, affecting initiation codon) were prioritised, and reviewed by searching the Online Mendelian Inheritance of Man database [http://www.omim.org] and the clinical-genetic literature. GTPBP2 variants were confirmed by Sanger sequencing.

\section{Results}

\section{Genetic findings}

Families 1 and 2 were both analysed in 2016, whereas family 3 was analysed in 2017. The WES evaluation strategy as outlined above flagged the homozygous GTPBP2 non-sense variants c. $1219[\mathrm{C}>\mathrm{T}] ;[\mathrm{C}>\mathrm{T}] \quad$ p. $(\mathrm{Gln} 407 *), \quad$ c. $1408[\mathrm{C}>\mathrm{T}]$; $[\mathrm{C}>\mathrm{T}]$ p. $\left(\operatorname{Arg} 470^{*}\right)$ and c.430[C>T];[C>T] p.(Arg144*) (NM_019096.4), respectively, and this was based on a single 2016 publication which suggested a homozygous GTPBP2 splice site variant to be causative for a complex neurological phenotype [5]. Sanger sequencing of the corresponding GTPBP2 exons confirmed the primary WES-based findings, and revealed complete segregation of c.1219[C>T]; $[\mathrm{C}>\mathrm{T}]$ with the phenotype (Fig. 1a). Segregation in families 2 and 3 could not formally been proven as only the index patients' DNA samples were available. All three GTPBP2 non-sense variants were submitted to the locus-specific database at the Leiden Open Variation Database (https://databases.lovd.nl/sha red/genes/GTPBP2); the corresponding individual identifiers are \#00121857, \#00121858, and \#00121859.

\section{Clinical findings}

Family 1 originates from Saudi Arabia. The index is a 6year-old female, the parents are first degree cousins, and family history is negative (Fig. 1a). The patient presented with a neurodevelopmental phenotype characterised by dysmorphic facial features, global developmental delay, postnatal microcephaly, failure to thrive, and optic atrophy. Brain MRI revealed hypogenesis of the corpus callosum, cerebellar hypoplasia, and Dandy-Walker malformation, but hypointensities suggestive of brain iron accumulation were not observed (Fig. 1c). A summary of the clinical and imaging findings is provided in Table 1 . Parents and unaffected siblings were heterozygotes or non-carrier of the c. $1219 \mathrm{C}>\mathrm{T}$ p.(Gln407*) GTPBP2 variant (Fig. 1a).
The second family is from Kuwait. The index is currently 10 years of age. His parents acknowledged to be distantly related, and several third- and fourth-degree relatives are similarly affected (Fig. 1b). The initially reported symptoms, i.e., intellectual disability and ectodermal dysplasia, were accompanied by seizures and a range of muscular/ skeletal abnormalities. The medical record also refers to an earlier MRI investigation, and mentions agenesis of the corpus callosum, but not hypointensities in the Globus pallidus or adjacent areas (Table 1).

The third family originates from Saudi Arabia. The index is a 2-year-old boy born to first degree cousins with negative family history (Fig. 1c). He presented from the 3rd month of life with global developmental delay. In addition, he had microcephaly, seizures, hypertonia, and choreoathetosis. He also has abnormal dentition and tooth colour, as well as sparse hair (Table 1, Fig. 1d). Brain MRI showed cerebellar hypoplasia and a thin corpus callosum (Supplementary Figure 1). The initial clinical suspicion had been Menkes disease, but this was ruled out by genetic testing of the ATP7A gene (Sanger sequencing and copynumber screening).

\section{Discussion}

Our study reports three novel families in which biallelic variants in $G T P B P 2$ are associated with a rare Mendelian disease. It thereby confirms the previously suggested pathogenic nature of complete GTPBP2 inactivation [5]. Many of the characteristics observed in the corresponding patients have a definite or at least potential neurological nature, with global developmental delay and intellectual disability being prime features. Additional shared symptoms include visual impairment (of different causes) and skeletal anomalies (scoliosis, pectus deformity). Remarkably, hair, teeth and/or skin abnormalities are also observed in all three families, but whether these observations are related to a more generalised ectodermal involvement needs further clarification.

Despite substantial clinical overlap between all reported families, clear differences are evident as well (Table 1). While the clinical phenotype of our patients is reminiscent of a neurodevelopmental disorder with structural brain abnormalities and severe intellectual disability, patients from the initially reported family presented with moderate intellectual disability, movement disorders and cerebellar atrophy. These differences may be explained by a generally wide phenotypic spectrum associated with GTPBP2 inactivation and/or by family-specific homozygous variants in additional genes as predicted for highly inbred populations [10]. Of note, the apparent discrepancies comprise MRIbased evidence for neurodegeneration with brain iron 
Table 2 Known variants in GTPBP2 which are predicted to trigger non-sense-mediated decay of the major isoform NM_019096.4, and to therefore represent bona fide loss-of-function variants

\begin{tabular}{|c|c|c|c|c|}
\hline Source & Variant & $\begin{array}{l}\text { Predicted consequence } \\
\text { at protein level }\end{array}$ & $\begin{array}{l}\text { Number of } \\
\text { independent } \\
\text { alleles }\end{array}$ & Zygosity \\
\hline \multirow{4}{*}{$\begin{array}{l}\text { Patients with } \\
\text { neurodevelopmental } \\
\text { phenotypes }\end{array}$} & c. $430 \mathrm{C}>\mathrm{T}^{\mathrm{a}}$ & p.(Arg130Ter) & 1 & Homozygous \\
\hline & c. $1219 \mathrm{C}>\mathrm{T}^{\mathrm{a}}$ & p.(Gln407Ter) & 1 & \\
\hline & c. $1237-1 \mathrm{G}>\mathrm{T}^{\mathrm{b}}$ & p.(Val413TrpfsTer3) & 1 & \\
\hline & c. $1408 \mathrm{C}>\mathrm{T}^{\mathrm{a}}$ & p.(Arg470Ter) & 1 & \\
\hline \multirow{7}{*}{$\begin{array}{l}\sim 60,000 \text { control } \\
\text { individuals (ExAC } \\
\text { database) }\end{array}$} & c.183_184insC & p.(Glu62ArgfsTer3) & 1 & Heterozygous \\
\hline & c. $424 \mathrm{C}>\mathrm{T}$ & p.(Arg142Ter) & 1 & \\
\hline & c. $655 \mathrm{C}>\mathrm{T}$ & p.(Arg219Ter) & 2 & \\
\hline & c.1214_1215insT & p.(Met405IlefsTer11) & 1 & \\
\hline & c. $1558 \mathrm{C}>\mathrm{T}$ & p.(Arg520Ter) & 1 & \\
\hline & c. $1561 \mathrm{C}>\mathrm{T}$ & p.(Arg521Ter) & 1 & \\
\hline & c.1666delG & p.(Arg556ValfsTer5) & 1 & \\
\hline
\end{tabular}

${ }^{\mathrm{a}}$ Present study

${ }^{\mathrm{b}}$ Ref. 5

accumulation (NBIA). The positive finding by Jaberi et al. [5]. prompted the authors to suggest that GTPBP2 may be a novel NBIA gene, while we did not observe suggestive MRI hypointensities in our patients. This negative finding could, however, be a consequence of earlier diagnosis and younger age of our patients. Additionally, differences in the magnetic resonance imaging technique applied (susceptibility-weighted by Jaberi et al. [5]. vs. T2*-weighted gradient-echo images in our case) may play a role. Still, the apparent lack of clinical progression and the extraneurological presentations would be rather atypical for NBIA [11, 12]. By additionally considering the very early onset, one may instead argue that the primary defect is of neurodevelopmental rather than neurodegenerative nature.

Such neurodevelopmental pathogenicity is also implied by findings in the earlier published mouse model. Before the first clinical-genetic report on GTPBP2 [5], a random mutagenesis-derived mouse line had been found to carry a homozygous Gtpbp2 splice site variant [6]. The associated pathology involved several types of neurons, but was CNSspecific; the resulting motor deficits were rapidly progressive, with death occurring at $\sim 2$ months of age. Notably, development of this phenotype depended on concomitant presence of a homozygous variant in a brain-specific tRNA. We therefore specifically checked whether our primary candidate gene lists (Supplementary Table 1) contain tRNA genes, but this was not the case. Moreover, a digenic background [13] can firmly be excluded in human patients, as it would predict many healthy carriers of biallelic $G T P B P 2$ inactivating variants. GTPBP2 data in the ExAC database (http://exac.broadinstitute.org), however, shows a high probability for loss-of-function intolerance (Table 2 and corresponding legend), supporting our hypothesis. The severely affected murine model of Ishimura et al. [6] in which CNS-specificity is apparently mediated by brainspecific expression of a certain tRNA, may therefore not directly be comparable with human patients. The proposed pathomechanism behind inactivation of GTPBP2/Gtpbp2, i.e., a detrimental effect on the translational machinery [14], is still likely to be shared. GTPBP2-associated disease may thereby be functionally related to certain peripheral neuropathies caused by variants in aminoacyl-tRNA synthatase genes [15].

We propose that, with the data at hand, classification of the GTPBP2-associated disease as an NBIA-subtype may be a premature conclusion. Further and older patients will have to be characterised to solve the issue, and to define the core features of the condition. That such patients can be identified in greater numbers is suggested by the fact that three of our $~ 9000$ clinically mixed exomes [7] turned out to be positive for homozygous truncating variants. GTPBP2-associated disease may, after all, be rare rather than ultra-rare. GTPBP2 should therefore be added to the growing list of genes that have to be considered during molecular diagnosis of hereditary neurodevelopmental disorders. 
Acknowledgements We thank the patients and their families for participating in the study. We acknowledge Christian Beetz and Harald Bruhn (both Jena University Hospital) and Prof. Cüneyt Calışır (Radiology Department, Eskisehir Osmangazi University) for support in the preparation of the manuscript.

\section{Compliance with Ethical Standards}

Conflict of interest A.M.B.-A., Z.Y., A.M., M.C., O.P., P.B., and A.R. are employees of Centogene A.G.; J.G.A. and O.B. are former employees of the company.

\section{References}

1. Parikshak NN, Gandal MJ, Geschwind DH. Systems biology and gene networks in neurodevelopmental and neurodegenerative disorders. Nat Rev Genet. 2015;16:441-58.

2. Liu YT, Lee YC, Soong BW. What we have learned from the next-generation sequencing: contributions to the genetic diagnoses and understanding of pathomechanisms of neurodegenerative diseases. J Neurogenet. 2015;29:103-12.

3. Matalonga L, Bravo M, Serra-Peinado C, et al. Mutations in TRAPPC11 are associated with a congenital disorder of glycosylation. Hum Mut. 2017;38:148-51.

4. Novarino G, Fenstermaker AG, Zaki MS, et al. Exome sequencing links corticospinal motor neuron disease to common neurodegenerative disorders. Science. 2014;343:506-11.

5. Jaberi E, Rohani M, Shahidi GA, et al. Identification of mutation in GTPBP2 in patients of a family with neurodegeneration accompanied by iron deposition in the brain. Neurobiol Aging. 2016;38:216 e211-216 e218.

6. Ishimura R, Nagy G, Dotu I, et al. RNA function. Ribosome stalling induced by mutation of a CNS-specific tRNA causes neurodegeneration. Science. 2014;345:455-9.

7. Trujillano D, Bertoli-Avella AM, Kumar Kandaswamy K, et al. Clinical exome sequencing: results from 2819 samples reflecting 1000 families. Eur J Hum Genet. 2017;25:176-82.

8. Wang K, Li M, Hakonarson H. ANNOVAR: functional annotation of genetic variants from high-throughput sequencing data. Nucleic Acids Res. 2010;38:e164.

9. Trujillano D, Oprea GE, Schmitz Y, Bertoli-Avella AM, Abou Jamra R, Rolfs A. A comprehensive global genotype-phenotype database for rare diseases. Mol Genet Genom Med. 2017;5:66-75.

10. Woods CG, Cox J, Springell K, et al. Quantification of homozygosity in consanguineous individuals with autosomal recessive disease. Am J Hum Genet. 2006;78:889-96.

11. Gregory A, Hayflick S. Neurodegeneration with brain iron accumulation disorders overview. In: Pagon RA, Adam MP, Ardinger $\mathrm{HH}$ et al. (eds). GeneReviews(R), Seattle (WA): 1993.

12. Schneider SA. Neurodegeneration with brain iron accumulation. Curr Neurol Neurosci Rep. 2016;16:9.

13. Darnell JC. Molecular biology. Ribosome rescue and neurodegeneration. Science. 2014;345:378-9.

14. Ishimura R, Nagy G, Dotu I, Chuang JH, Ackerman SL. Activation of GCN2 kinase by ribosome stalling links translation elongation with translation initiation. Elife. 2016;5: e14295.

15. Wallen RC, Antonellis A. To charge or not to charge: mechanistic insights into neuropathy-associated tRNA synthetase mutations. Curr Opin Genet Dev. 2013;23:302-9. 